\title{
Officiating Role Influences the Physical Match Activity Profiles of Rugby League Touch Judges and Referees
}

\author{
by \\ Leesa Pearce ${ }^{1}$, Carl Woods ${ }^{1}$, Wade Sinclair ${ }^{1}$, Anthony Leicht ${ }^{1}$
}

\begin{abstract}
This study investigated the effect of the officiating role on physical activity profiles of rugby league match officials during match-play. Physical performance indicators were collated from 23 match officials, resulting in 78 observations. Match officials were categorised into two groups: referees and touch judges. Microtechnology facilitated the quantification of total distance $(\mathrm{m})$, relative distance $\left(\mathrm{m} \cdot \mathrm{min}^{-1}\right)$, maximum velocity $\left(\mathrm{m} \cdot \mathrm{s}^{-1}\right)$, the percentage of high intensity running distance $\left(\%\right.$ total $\left.>3.01 \mathrm{~m} \cdot \mathrm{s}^{-1}\right)$, walking distance $\left(<1 \mathrm{~m} \cdot \mathrm{s}^{-1}\right)$, jogging distance $\left(1.01-3 \mathrm{~m} \cdot \mathrm{s}^{-1}\right)$, fast jogging distance (3.01 - $5 \mathrm{~m} \cdot \mathrm{s}^{-1}$ ), and sprinting distance ( $\left.>5 \mathrm{~m} \cdot \mathrm{s}-1\right)$. Multivariate analysis modelled the main effect of the officiating role with follow up univariate analyses identifying significant differences. A significant effect was noted $(V=750 ; F(8,66)=24.71 ; p<0.05)$ with referees covering a greater total distance $(7767 \pm 585$ vs. $7022 \pm 759 \mathrm{~m})$, relative distance $\left(90 \pm 6\right.$ vs. $\left.82 \pm 8 \mathrm{~m} \cdot \mathrm{min}^{-1}\right)$, jogging distance (3772 \pm 752 vs. $3110 \pm 553 \mathrm{~m}$ ), and fast jogging distance ( $2565 \pm 631$ vs. $1816 \pm 440 \mathrm{~m}$ ) compared to touch judges. Touch judges covered greater distances while sprinting (1012 \pm 385 vs. $654 \pm 241 \mathrm{~m}$ ). Results provide important guidance in the development of training programs for match officials.
\end{abstract}

Key words: microtechnology; referee; team sport; performance analysis.

\section{Introduction}

Not dissimilar to other football codes, rugby league (RL) can be characterised as an intermittent team sport that requires players to combine high intensity running efforts with periods of lower-intensity activity (Gabbett et al., 2012). This characterisation stems from the wealth of literature that has profiled the movement demands of players amongst differing levels of competition (Gabbett, 2013, 2012; Johnston et al., 2014; Kempton et al., 2014). However, the movement profiles of RL match officials appear to be slightly more ambiguous, with the scarcity of notational research focused toward these important match participants. Generally, there are two types of RL officials: the middle referee, who enforces the laws of the game and imposes penalties when breached, and the touch judges, who assist with matters relating to the sidelines (referred to as touch) and end of the field (referred to as touch in-goal) play (Australian Rugby League Commission, 2015).

Given the focused roles of the middle referee and touch judges, it could be expected that both may exhibit different physical match activity profiles. For example, the middle referee presides over the $100 \times 68 \mathrm{~m}$ rectangular playing field, continually adjusting their field position to remain alongside the play of the ball. In contrast, the touch judges move along the boundary of the playing field and within the in-goal area at each end of the playing field during goal kicks. Immediately following the goal kick ruling, the touch judges sprint to the sideline position at the opposite end of the field so the game may resume

1 - port and Exercise Science, James Cook University, Townsville, Queensland. 
play. Differences between match official movement profiles during match-play are demonstrated in other team intermittent sports (Barbero-Álvarez et al., 2012). Most notably, significant differences in external demands have been observed in soccer, with field referees accumulating greater distances at low, moderate, and vigorous intensity velocities when compared to boundary referees (Barbero-Álvarez et al., 2012). Pertinently, the authors highlighted the importance of tailoring specific training programs for soccer officials of different adjudicative roles, suggesting that the different roles should be considered when designing strength and conditioning programs to enhance match performance (Barbero-Álvarez et al., 2012).

Preliminary research on RL match officials has, to date, examined the middle referee role for elite competition demonstrating that elite RL referees (NRL; premier RL competition within Australia and New Zealand and English Super League) cover average total distances between 6,700 to 8,900 m during match-play (Hoare, 2008; Kay and Gill, 2003; Murray, 1988). Moreover, middle referees have been reported to spend more than $67 \%$ of these distances at speeds less than 1.94 m.s-1 (Hoare, 2008; Kay and Gill, 2003; Murray, 1988). Despite only being conducted on middle referees, the above cited work has provided a basis for the development of training interventions reflective of match-play demands. Prior work investigating the activity demands of sub-elite match officials examined the internal response of both touch judges and middle referees during competition (Pearce et al., 2015). Sub-elite RL officials exhibited considerable physiological stress during match-play, with both middle referees and touch judges demonstrating similar cardiovascular stress during competition (Pearce et al., 2015). However, the middle referees reported a greater RPE post-match compared to the touch judges of the same game. The authors suggested that this greater perception of effort represented increased psychological stress due to the primary adjudicative responsibilities of the middle referee during competition (Pearce et al., 2015).

Consequently, investigating both middle referees and touch judges may provide more comprehensive scaffolding for the development of training interventions specific to the officiating role. Informed exercise prescription cannot be underemphasised, with recent work suggesting that a RL official's perceptual-cognitive skill (i.e., decision-making) may be impaired under physiologically fatiguing conditions (e.g. late in the match) (Emmonds et al., 2015). In acknowledgement of this, the NRL introduced two middle referees (main referee and pocket referee) in 2009 (Australian Rugby League Commission, 2015). However, this addition has not yet extended to sub-elite RL competitions, with competitions still officiated with a traditional sequence (e.g. one middle referee, and two touch judges).

To this end, there is yet to be a study investigating whether the physical activity profiles of sub-elite match officials differ according to the officiating role during RL matchplay. This study aimed to address this gap by comparing the physical activity profiles of middle referees and touch judges during competition. Given the unique requirements of each officiating role in other sports (Barbero-Álvarez et al., 2012) and anecdotally for RL (unpublished observations), it was hypothesised that middle referees would accrue a greater total distance coupled with a reduced high intensity running distance in comparison to touch judges. Subsequent findings may provide important practical applications for the establishment of physical training interventions for RL match officials.

\section{Methods}

A quantitative cross sectional observational research design was used to address the study hypothesis. The James Cook University Human Research Ethics Committee provided ethical approval, and written informed consent was obtained from all participants prior to the study commencement. All experimental procedures were in accordance with the international standards for sport and exercise science research (Harriss and Atkinson, 2013).

The activity profiles of match officials originating from two semi-elite competitions were quantified across a total of 26 matches.

\section{Participants}

A total of 23 referees $(29.6 \pm 10.3 \mathrm{y} ; 180.6 \pm$ $8.7 \mathrm{~cm} ; 83.9 \pm 12.8 \mathrm{~kg}$ ) officiating in two semi-elite competitions within Australia volunteered to 
participate in this study. Each match official had been training regularly subsequent to the preseason in early November (2-3 sessions per week at a moderate to high intensity) and had met the fitness level criteria stipulated by the relevant referee associations. Match officials were then split into two groups based upon their officiating role during each match: middle referees or touch judges, with the physical profiles of both officiating groups then being compared to test the study hypothesis.

\section{Measures}

Data were collected over the course of 26 matches resulting in a total of 78 observations. Prior to the main analyses being conducted in this study, the match activity demands of officials from the two competitions were compared to ensure homogeneity between the two competitions, with no significant differences being noted $(p>0.05)$. From a total of 78 observations, 26 were contributed from the middle referees and 52 from the touch judges. The uneven spread in match official observations was due to the officiating rules imposed by the Australian Rugby League Commission (2015), and was somewhat inevitable. The activity profiles of both officiating groups were examined across the first half, second half and entire match.

\section{Procedures}

Microtechnology was used to quantify the physical match activity profiles of all officials participating in this study. Specifically, each official wore a scapula mounted, portable minimaxX global positioning system (GPS) unit (Catapult Innovations, Team Sport 5.0, Firmware 6.54, $10 \mathrm{~Hz}$, Melbourne, Australia) in a pouch embedded within a harness underneath their communications vest. Prior to data collection, each match official role was allocated with one GPS unit, which they wore throughout the entire data collection period. In accordance with the recommendations from previous research (Jennings et al., 2010), the antennas of each unit were exposed to ensure each had clear satellite reception. The mean number of satellites facilitating GPS lock during data collection was 10 \pm 2 , and the mean horizontal dilution of position (HDOP) was $1.2 \pm 0.1$. The HDOP provides an indication of the positional signal determined by the geometrical organisation of the satellites accuracy with values usually ranging from 1 to 50
(Witte and Wilson, 2004). A higher HDOP value (i.e., closer to 50) indicates an unreliable positional fix, while a lower value (i.e., closer to 1) indicates a reliable positional fix with one satellite being directly overhead, and the remainders spaced equally along the horizon (Witte and Wilson, 2004). The data were downloaded after each match using propriety analysis software (Catapult Sprint Version 5.0.92, Melbourne, Australia) and the output file was exported to Excel (Microsoft, Redmond, USA) for analysis. Only active match time' was analysed with the halftime interval omitted prior to analysis.

The criterion variables examined in the current study were similar to previous research (Hulin and Gabbett, 2015; Woods et al., 2015); specifically, total distance $(\mathrm{m})$, relative distance $\left(\mathrm{m} \cdot \mathrm{min}^{-1}\right)$, maximal velocity $\left(\mathrm{m} \cdot \mathrm{s}^{-1}\right)$, high intensity running (speeds $>3.01 \mathrm{~m} \cdot \mathrm{s}^{-1}$; Woods et al., 2015) distance expressed as a percentage of total distance examined. Additionally, distances (m) covered while performing different locomotive activities were calculated being defined as: walking $\left(<1 \mathrm{~m} \cdot \mathrm{s}^{-1}\right)$, jogging $\left(1.01-3 \mathrm{~m} \cdot \mathrm{s}^{-1}\right)$, fast jogging $\left(3.01-5 \mathrm{~m} \cdot \mathrm{s}^{-1}\right)$, and sprinting $\left(>5.01 \mathrm{~m} \cdot \mathrm{s}^{-1}\right)$ (Gabbett, 2012; Veale et al., 2008). The $10 \mathrm{~Hz}$ minimaxX GPS unit had demonstrated acceptable clinometric properties when quantifying these listed match and locomotive metrics (Jennings et al., 2010; Johnston et al., 2014).

\section{Statistical Analysis}

In order to profile the entire movement demands of each match official group, descriptive statistics (mean \pm standard deviation) were calculated for all criterion variables. Multivariate analysis of variance (MANOVA) modelled the main effect of match officials (two levels: middle referee, touch judge) separately across the first half, second half, and entire match. Statistical significance was interpreted using the Pillai's trace $(V)$ with follow up univariate analysis of variance (one-way ANOVA) used to identify which, if any, criterion variable(s) significantly differed according to the main effect. Additionally, effect size (d) statistics were calculated with $d=0.01-0.20$ considered small, $d$ $=0.21-0.50$ considered moderate, $d=0.51-0.80$ considered large, and $d>0.81$ considered very large (Cohen, 1988). All comparisons were undertaken using the SPSS software (Version 22, SPSS Inc., Armonk, New York) and the Type-I 
error rate was set at $\alpha<0.05$.

\section{Results}

The descriptive statistics for each match official group are displayed in Table 1. The MANOVA revealed a significant effect for the first half $(V=0.66 ; F(8,66)=16.21 ; p=0.00)$, second half $(V=0.71 ; F(8,66)=20.19 ; p=0.00)$, and entire match $(V=0.75 ; F(8,66)=24.71 ; p=0.00)$. Follow up analysis indicated that middle referees covered a greater total distance and relative distance in the first half, second half and entire match compared to touch judges (Table 1). These significant differences corresponded to moderate to large effect sizes ( $d=0.40-0.63)$. Additionally, middle referees experienced a significantly greater maximum velocity during the second half and entire match compared to touch judges (Table 1).

As illustrated in Figure 1, middle referees covered a greater total distance while jogging (Figure $1 \mathrm{~B}, d=0.51$ ) and fast jogging (Figure $1 \mathrm{C}$, $d=0.70$ ) during each half and entire match in comparison to the touch judges. Conversely, touch judges travelled a significantly greater total sprinting (Figure 1D, $d=0.57$ ) distance during entire match-play when compared to the middle referees.

\section{Discussion}

The aim of this study was to compare the physical match activity profiles of RL middle referees and touch judges. Results indicated that middle referees covered a greater total distance, relative distance, jogging distance, and fast jogging distance during match-play when compared to the touch judges. In contrast, touch judges accumulated a greater total sprinting distance compared to middle referees during competition. These results demonstrate distinctive physical activity profiles specific to the adjudicative role in RL match officials.

Table 1

Middle referee and touch judge physical activity profiles (mean \pm standard deviation) exhibited during the first half, second half and total match.

\begin{tabular}{|c|c|c|c|c|c|c|c|c|c|}
\hline \multirow[b]{2}{*}{$\begin{array}{c}\text { Movement } \\
\text { Category }\end{array}$} & \multicolumn{3}{|c|}{ First Half } & \multicolumn{3}{|c|}{ Second Half } & \multicolumn{3}{|c|}{ Total Match } \\
\hline & $\begin{array}{l}\text { Middle } \\
\text { Referee }\end{array}$ & $\begin{array}{l}\text { Touch } \\
\text { Judge }\end{array}$ & $d$ & $\begin{array}{l}\text { Middle } \\
\text { Referee }\end{array}$ & $\begin{array}{l}\text { Touch } \\
\text { Judge }\end{array}$ & $d$ & $\begin{array}{l}\text { Middle } \\
\text { Referee }\end{array}$ & $\begin{array}{l}\text { Touch } \\
\text { Judge }\end{array}$ & $d$ \\
\hline Total distance $(\mathrm{m})$ & $3880 \pm 344$ & $3547 \pm 397^{*}$ & 0.45 & $3896 \pm 289$ & $3475 \pm 439^{*}$ & 0.58 & $7767 \pm 585$ & $7022 \pm 759^{*}$ & 0.55 \\
\hline $\begin{array}{l}\text { Relative distance } \\
\left(\mathrm{m} \cdot \mathrm{min}^{-1}\right)\end{array}$ & $90.2 \pm 7.8$ & $82.8 \pm 10.6^{*}$ & 0.40 & $90.5 \pm 6.9$ & $81.2 \pm 7.8^{*}$ & 0.63 & $90.2 \pm 6.4$ & $82.0 \pm 8.1^{*}$ & 0.56 \\
\hline $\begin{array}{l}\text { Maximum velocity } \\
\left(\mathrm{m} \cdot \mathrm{s}^{-1}\right)\end{array}$ & $7.1 \pm 0.7$ & $6.8 \pm 0.9$ & 0.02 & $7.1 \pm 0.6$ & $6.6 \pm 0.7^{*}$ & 0.38 & $7.1 \pm 0.5$ & $6.7 \pm 0.8^{*}$ & 0.31 \\
\hline $\begin{array}{l}\text { High intensity } \\
\text { running (\%) }\end{array}$ & $0.4 \pm 0.6$ & $0.4 \pm 0.8$ & 0.00 & $0.4 \pm 0.5$ & $0.4 \pm 0.7$ & 0.02 & $0.4 \pm 0.1$ & $0.4 \pm 0.1$ & 0.05 \\
\hline
\end{tabular}

$d$-effect size; Note: * $p<0.05$ vs. Middle Referee 


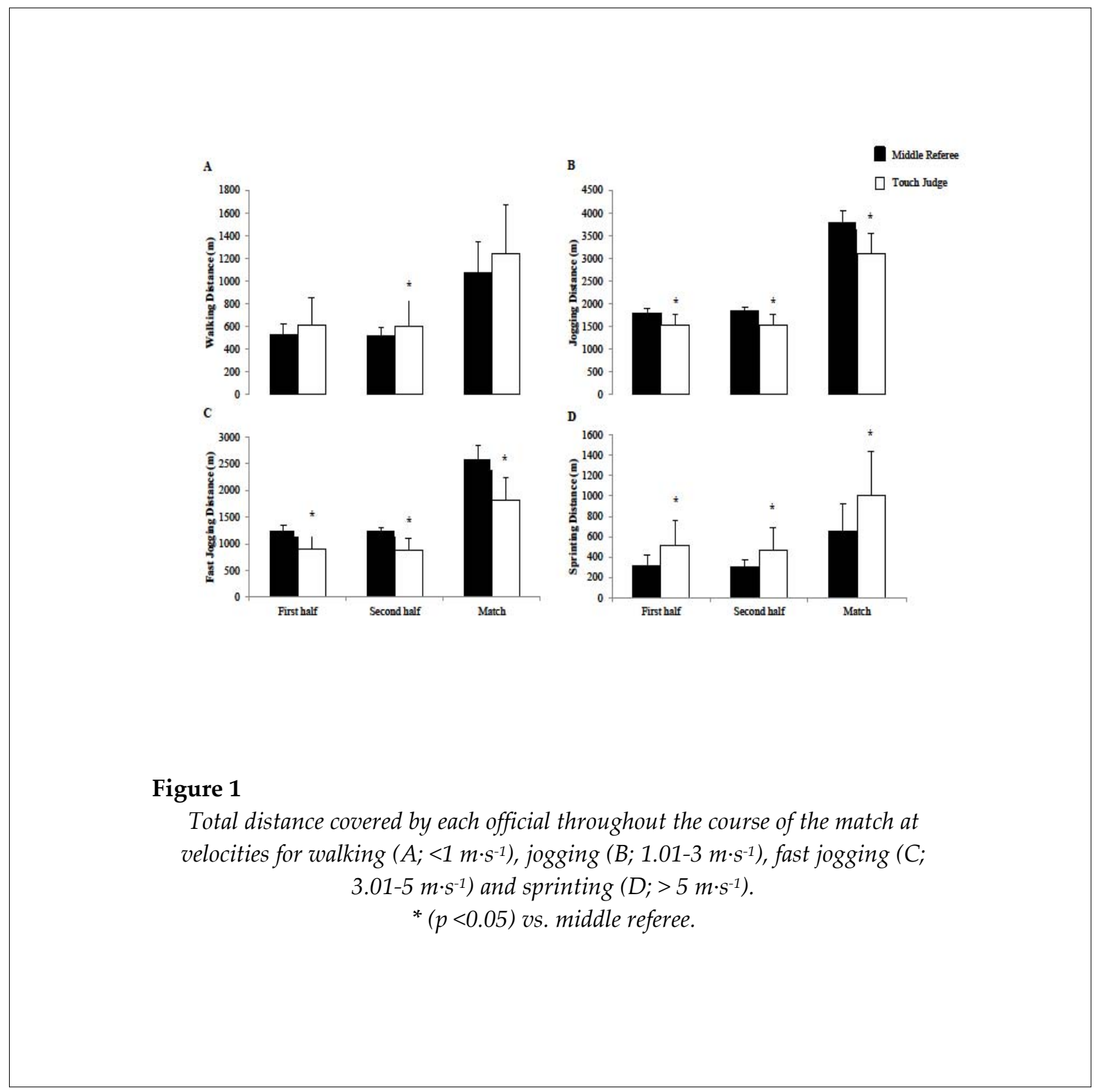

The distinctive profiles noted between the two match official groups may be explained by the unique adjudicative roles performed during match-play. For example, the middle referee often remains in close proximity to the ball carrier in order to adjudicate each passage of play. In contrast, the touch judges move parallel to the line of play, along the field boundary. Moreover, touch judges perform long sprinting actions to the opposite end of the field following attempted goal kicks. As such, it was hypothesised that middle referees would accrue a greater relative distance per minute of match-play given they are required to stay in close proximity of the ball carrier. Similarly, touch judges were hypothesised to accrue a greater total distance while sprinting, given their match-play interaction. Subsequently, both study hypotheses were supported by the results presented here.

Differences have been demonstrated for official types in other intermittent team sports (Barbero-Álvarez et al., 2012). Notably, soccer middle referees have been reported as requiring greater reliance on their aerobic energy system due to covering greater distances at low, moderate, and high intensity velocities in comparison to boundary referees (BarberoÁlvarez et al., 2012). The current study identified distinctive physical activity profiles for both middle referees and touch judges in RL. 
Specifically, middle referees were generally characterised by continuous jogging and fast jogging actions, while touch judges were generally characterised by sprinting actions interspersed with jogging. Consequently, there are critical practical implications to stem from this work. Primarily, it is recommended that strength and conditioning specialists consider both match official roles when developing a physical training program, particularly as match officials in RL subelite competitions undertake both roles throughout the season (e.g. middle referee in the first match; touch judge during the second match). Therefore, the program should include training adaptation for both roles; for example, prolonged running intervals at moderate to high velocities (between 3 to $5 \mathrm{~m} \cdot \mathrm{s}-1$ ), change of direction and change of the pace as demonstrated by middle referees, and sprinting efforts at distances between 80 to $100 \mathrm{~m}$ (to reflect the field size), with power and acceleration tasks, as demonstrated by touch judges during competition. Lastly, the application of microtechnology (GPS) analyses extended beyond players, as they appear beneficial for match officials when quantifying activity profiles with the intention of developing match-specific training interventions.

This study is not without limitations and areas in which future should progress. Specifically, given this was a preliminary study quantifying the external demands of RL match officials, it did not quantify contextual and situational variables which may influence a RL official's activity profile. Thus, future work may wish to consider investigating the influence that contextual variables, such as time of day and/or environmental conditions, and situational variables such as score margin and opposition quality, have on the physical activity profiles of RL match officials. The addition of such work may further highlight the idiosyncrasies present between match officials of differing adjudicative roles, enabling the thorough establishment of informed and targeted training interventions. Thus, the current findings provide an enticing platform for which future work could progress as well as the evidence-based identification of competition demands for sub-elite RL match officials for coaching staff to develop purposeful systematic training programs.

\section{Acknowledgements}

The authors would like to thank the relevant Referee Associations for their support and assistance with data collection. This research did not receive any specific grant from funding agencies in the public, commercial, or not-for-profit sectors.

\section{References}

Australian Rugby League Commission. Rugby League Laws of the Game International Level with Notes on the Laws and NRL Telstra Premiership Interpretations; 2015

Barbero-Álvarez J, Boullosa DA, Nakamura FY, Andrín G, Castagna C. Physical and physiological demands of field and assistant soccer referees during America's cup. J. Strength Cond. Res., 2012; 26: 1383-1388

Cohen J. Statistical power analysis: A computer program. Routledge; 1988

Emmonds S, O'Hara J, Till K, Jones B, Brightmore A, Cooke C. Physiological and movement demands of rugby league referees: Influence on penalty. J. Strength Cond. Res., 2015; doi:10.1519/jsc.0000000000001002

Gabbett TJ. Influence of playing standard on the physical demands of professional rugby league. J. Sports Sci., 2013; 31: 1125-1138

Gabbett TJ. Sprinting patterns of national rugby league competition. J. Strength Cond. Res., 2012; 26: 121-130 doi:10.1519/JSC.0b013e31821e4c60

Gabbett TJ, Jenkins DG, Abernethy B. Physical demands of professional rugby league training and competition using microtechnology. J. Sci. Med. Sport, 2012; 15: 80-86 doi:10.1016/j.jsams.2011.07.004 
Harriss DJ, Atkinson G. Ethical standards in sport and exercise science research: 2014 update. Int. J. Sports Med., 2013; 34: 1025-1028

Hoare K. Physiological demands of NRL match officiating. J Aust Strength and Cond, 2008; 16: 38-42

Hulin BT, Gabbett TJ. Activity profiles of successful and less-successful semi-elite rugby league teams. Int. J. Sports Med., 2015; 36: 485-489

Jennings D, Cormack S, Coutts AJ, Boyd L, Aughey RJ. The validity and reliability of GPS units for measuring distance in team sport specific running patterns. Int. J. Sports Physiol. Perform., 2010; 5: 328341

Johnston RD, Gabbett TJ, Jenkins DG. Applied sport science of rugby league. Sports Med., 2014; 44: 1087-1100

Johnston RJ, Watsford ML, Kelly SJ, Pine MJ, Spurrs RW. Validity and interunit reliability of $10 \mathrm{~Hz}$ and 15 Hz GPS units for assessing athlete movement demands. J. Strength Cond. Res., 2014; 28: 1649-1655 doi:10.1519/JSC.0000000000000323

Kay B, Gill ND. Physical demands of elite rugby league referees: Part one - Time and motion analysis. J. Sci. Med. Sport, 2003; 6: 339-342 doi:http://dx.doi.org/10.1016/S1440-2440(03)80027-0

Kempton T, Sirotic AC, Coutts AJ. An integrated analysis of match-related fatigue in professional rugby league. J. Sports Sci., 2014; 33: 39-47 doi:10.1080/02640414.2014.921832

Murray P. Training programs for rugby league referees: Some results and suggestions. NSWRL Referees Association; 1988

Pearce LA, Woods CT, Sinclair WH, Leicht AS. Impact of role on internal demands in officials during subelite rugby league matches. J Aust Strength and Cond, 2015; 23: 3

Veale JP, Pearce AJ, Koehn S, Carlson JS. Performance and anthropometric characteristics of prospective elite junior Australian footballers: A case study in one junior team. J. Sci. Med. Sport, 2008; 11: 227-230

Witte TH, Wilson AM. Accuracy of non-differential GPS for the determination of speed over ground. J. Biomech., 2004; 37: 1891-1898

Woods CT, Joyce C, Robertson S. What are talent scouts actually identifying? Investigating the physical and technical skill match activity profiles of drafted and non-drafted U18 Australian footballers. J. Sci. Med. Sport, 2015; doi:10.1016/j.jsams.2015.04.013

\section{Corresponding author:}

\section{Leesa Pearce}

Sport and Exercise Science, James Cook University, Townsville, Queensland, Australia

Phone: 61747814252

E-mail: leesa.pearce@jcu.edu.au 